Oersted contends that if these secondary unilocular spores are sown upon young plants of the Sorbus aucuparia, they will germinate, and that the ends of the germinating filaments penetrating the tissues of the leaf of the sorb will in turn produce the spermagonia and peridia of Rostelia cornuta. This is very similar to the deductions of Prof, de Bary that the spores of the AEcidium which flourishes on the berberry may be employed to inoculate young plants of wheat, and will produce as a result the wheatmilduw (Puccinia graminis), which he contends is another generation of the berberry fungus completed upon a different host. (See NATURE, vol. ii. p. 3r8)

Such experiments as those of Professors Oersted and De Bary must always prove unsatisfactory unless performed with extraordinary care, and until confirmed by o:her observers. One or two strong presumptions can always be urged against them, and require to be boldly faced. Wheat is very subject to the attacks of mildew (Puccinia ), and the results claimed for certain experiments are that they have produced by inoculation with other spores the common Puccinia upon wheat plants, to which the wheat is particularly addicted all the world over. Admitting that the Ecidium spores sown on the leaves of young wheat plants germinate, and that the germinating filaments enter the tissues of the leaf, are we therefore justified in affirming, or admitting that the inoculating spores produce the Puccinia which ultimately exhibits itself? Is it not more feasible to believe that the germination of the foreign spores have only served to stimulate the latent germs of the Puccinia already present in the tissues of the wheat plant? What guarantee is afforded by those who have already experimented, that the wheat plants experimented upon would not ultimately, without inoculation, have developed precisely the same parasite as that supposed to have been produced by inoculation? Assuming also that the experiment was pursued in the opposite direction, and that the spores of the wheat mildew were sown upon young plants of the berberry, if the Ecidium should soon afterwards appear on the leaves, it is easy enough to jump to the conclusion that they were produced by inoculation, but assumption is insufficient since the berberry is very subject, year after year, to bear on some of its leaves the peridia of the Acidium. What evidence could be given that the Acidium would never have appeared but for the inoculation? It is manifest that no amount of care in cultivation under bell glasses or other exclusion from foreign influences is sufficient against a contingency which dates back to the seed of the nurseplant.

If the sowing of the spores of Acidium upon the leaves of wheat resulted in the production of an Acidium identical with it, or if the inoculation of berberry with wheat mildew was succeeded by the development of a Puccinia of a very similar character, it would not be so difficult to believe in both cases that the resulting forms might have been caused by inoculation. When the fungi assumed to be produced by inoculation are those to which the nurseplants are particularly and specially subject, the evidence should be very strong before it is affirmed that a very natural phenomenon had an unnatural * cause.

The evolution of Restelia on the leaves of the "mountain ash" by inoculation with Podisoma spores is quite analogous to the berberry and wheat fungi. It is common enough to find the Podisoma on junipers, and the Rostelia on "mountain ash," and the presumption would be, if young plants of "mountain ash" were covered up ever so carefully with bell glasses, notwithstanding that the leaves had been sprinkled with the spores of a dozen other species of fungi, if Restelia made its appearance, that it bore no relation whatever to any of the foreign spores which had been sown upon it, but would have been there

* The term " unnatural" is employed here in the sense that the presumed cause is one of which we have no experience, and which is contrary to the ordinary course of nature. independent of inoculation, or bell glasses, or a dozen like contingencies.

In both cases to which allusion has been made above, there is need of the strongest evidence to show that the ultimate parasite would not have made its appearance but for the inoculation, or that the whole chain was completed which connected the inoculating spore with the parasite produced. It would be folly to contend against facts for the sake of theory, and absurd to combat conclusions fairly deduced from ascertained facts; but in this instance we arc bound iv contend, in honesty to our convictions, that in neither case has Oersted or De Bary shown to our satisfaction that they were justified in declaring for an alternation of generations of fungi in which the stages were passed on different nurse plants. When the facts are confirmed and established will be lime enough to inquire whether boih stages are essential the one to the other, and, if so, how it is that mildewed wheat in such great profusion can be found in districts where berberry bushes are unknown, or why the Rastelia on the leaves of pear trees should be so common in counties where scarcely a savin can be found.

I have been led to these o'jeervations partly because some writers have accepted the conclusions at once as if they were incontrovertible facts, and partly because I have personally been charged with ignoring (by silence, it is presumed) the results of De Bary and Oersted's expesiments, whereas I only claim the privilege of cloubting where I would not dare to deny.

M. C. CoOke

\section{THE SCIENCE AND ART DEPARTMENT}

$T$ HE following important Minute on the subject of 1 Science instruction has recently been issued by the Committee of the Privy Council on Education :-

It appears desirable that the instruction of students in Science, after they have completed the course of the ordinary elementary school, should be carried on more methodically than is at present the case, and that they should not attempt to grapple with the more advanced forms of Science until they have received sound and practical instruction in those subjects which constitute the groundwork of all the physical sciences.

To this end the course of instruction specified below has been prepared as adapted both to secondary day schools and to night classes.

It will depend on circumstances, especially if the student can only attend night classes, how many subjects he can take up in one year. It must therefore be understood that the course should not only comprise the subjects named below, but also that they should be taken in the order in which they are stated.

The terminology used is that of the Science and Art Directories. The syllabus of subjects there given states precisely what is included under each head. And it is assumed that before commencing the following course, the student will have been made acquainted, in the elementary school, with the elements of arithmetic, and the primary conceptions of physical science.

COURSE OF INSTRUCTION.-First Year.-Mathematics (Subject V., First Stage) ; Freehand Drawing (2nd Grade Art); Practical Plane Geometry (2nd Grade Art); Elementary Mechanics, including the physical properties of liquids and gases (Subject VI., First Stage); Physics : Acoustics, Light and Heat (Subject VIII., First Stage). Second Year.-Chemistry, Inorganic (Subject X., First Stage), with practical work; Physics: Magnetism and Electricity, frictional and voltaic (Subject IX., First Stage); Mathematics (Second Stage and, if possible, Fourth' Stage, Subject V.) ; Practical Geometry, Plane and Solid (Subject I., First Stage); Animal Physiology, if possible (Subject XIV., First Stage). The student 
should also, during the first and second year, work at mechanical drawing as provided for in the Art Directory, Stage 23a. Third Year.-The work of this year must depend so much on the student's aptitude, and the progress he has made in the preceding course, that it is impossible to lay down the subjects for the third year's course with any definiteness. It is essential that before continuing his course, or commencing new subjects, he should have a sound knowledge of the first stage of Mathematics, Elementary Mechanics, Physics, and Chemis. try; that he should have such a knowledge of practical Geometry and Mechanical Drawing as to be able to draw and read simple plans, elevations, and sections with readiness, and that he should have sufficient facility in Freehand Drawing to make clear and neat explanatory diagrams.

When these subjects have been mastered, the student should, while continuing his studies in mathematics, take up the first stage of Animal Physiology, if he has not already done so. He will then be in a position to specialise his studies with advantage in one of the following groups, according to his requirements, taking up, for instanceI. Physics and Chemistry and Metallurgy ; 2. Theoretical and Applied Mechanics, Steam, and Machine Construction and Drawing; 3. Theoretical and Applied Mechanics, and Building Construction and Drawing; 4. Biology; 5. Geology, Physical Geography, Mineralogy, and Mining. The student may also with advantage continue his freehand drawing and practical geometry.

The foregoing course is framed to lay the foundation of a thorough and systematic scientific training. It must, however, be understood that this course, though strongly recommended for all those who can devote sufficient time to go through it, in no way supersedes or does away with the power of holding special classes in different subjects for those who have not these opportunities, or diminishes the aid at present offered to such classes,

The fact of the course.being intended as a systematic training will also explain the omission of certain subjects which are not to be considered unimportant because they fincl no place in the course. Thus systematic Botany will be found of very great use as a preliminary to the study of natural science. As such it may be taught in elementary schools before this course is commenced. But, further than that, it cannot be considered a step in a sys. tematic course till the student takes it up as a portion of Biology in his third year. In the same way Physical Geography is a subject which may with great advantage be studied in all schools, and is especially adapted for students who cannot go through a systematic course. The first elements of Physical Geography, treating broadly the outlines of physical science and describing its objects, should, as stated above, be taught as an introduction to its systematic study. But Physical Geography in its general sense covers so wide a field, embracing to a greater or less degree so many branches of Science, that it does not fall into a systematic course of training in science, though as a means of imparting highly valuable general information, as distinct from a systematic training, it may be strongly recommended.

\section{ARCTIC EXPLORATIONS}

$A \mathrm{~N}$ excellent paper on the above subject appears in NATURE of Nov. 30, and it is to be hoped that it may have the desired effect of reanimating in our Government and among scientific men' a fresh interest in the prosecution of a further survey of the unknown seas round the Pole.

Agreeing as I do with the writer as to the great importance of such an exploration as he recommends, I cannot so readily acknowledge the correctness of his opinion as to the advantages of the route by Smith Sound over that along the west shore and to the north of Spitzbergen, from which point Parry the greatest and noblest of arctic explorers) attempted to reach the Pole with boat sledges in 1827 .

Parry had, I think, on this occasion chosen the right route, but the wrong season of the year ; for he attempted the journey in the month of July, instead of in March, April, May, and June.

At Spitzbergen a vessel can always get as far as $80^{\circ}$ north, probably higher; for Mr. Lamont has, during the last two summers, on his pleasure cruises, readily reached the latitude named.

I had it from the great navigator Parry himself, that the ice he saw to the north of Spitzbergen would not have been difficult to travel over at the proper season of the year.

The farthest north point reached with much difficulty by ships in Smith Sound has been $78^{\circ} 40^{\prime}$, and we have not the least. warrant or certainty that any future expedition may be able to winter its ship or ships nearer the Pole by this route.

From lat. $78^{\circ} 40^{\prime}$ the distance to the Pole is 680 geographical miles, making the journey there and back $I, 360$ miles in a straight line.

But surely no experienced Arctic traveller would be sanguine enough to believe that he could take a "bee line" in a sledge journey to the Pole ; in fact, he would require to make an allowance of about one-fifth for obstructions by rough ice, probable contour of coast line, \&c., so that the actual distance to be made would be $1,360+270=$ I,630 geographical miles, a journey 200 or 300 miles longer than any that has yet been accomplished, even by that admirable Arctic traveller, the late Lieut. Mecham. Yet Mecham, in his two longest journeys of 1,200 or 1,300 miles each (I forget whether these are geographical or statute miles, but I think they are the latter), had advantages not likely to be found in a journey to the Pole. On the one occasion deer, musk-cattle, and other game were so abundant and so tame that he could and did easily kill as many as the party required, and could have killed many more. On the other occasion he was travelling along a known route, at several points of which depots of provisions had been placed by ships wintering there, or by other means, from which he was enabled to obtain supplies both on the outward and homeward march.

Mr. Markham says that a ship can always get so far north in Smith Sound that the Pole can be reached by a journey from it with sledges of 968 miles there and back.

By what powers of reasoning or rule of arithmetic this conclusion has been arrived at I am at a loss to know, unless there is always a certainty of ships getting into winter quarters in Smith Sound as far up as $82^{\circ}$ latitude, yet Kane was stopped 200 miles south of this, and Hayes even at a greater distance.

The Spitzbergen route has never had a fair trial with sledges over ice either with or without the aid of dogs, and I believe that if the Pole is ever to be reached, it will be by it, and not by Smith Sound. The distance to be travelled will not probably be less than $\mathrm{I}, 400$ geographical miles, possibly more, a journey practicable enough under favourable circumstances, but by no means easy of accomplishment.

JOHN RAE

\section{NOTES}

AT the Anniversary Meeting of the Fellows of the Royal Society on Thursday last, Lieut.-General Sir Edward Sabine, R.A., K.C.B., resigned the office of president, which he has filled since 186I, and the Astronomer Royal was elected to fill the presidential chair. The following gentlemen were appointed officers and council for the ensuing year :--President : George Biddell Airy, M.A., D.C.L., LL.D., Astronomer Royal. Treasurer : William Spottiswoode, M.A. Secretaries: William Sharpey, M.D., 